\title{
PRESIDENTS PAGE
}

\section{Academic Leadership for the Next Decade}

\author{
BakUl Jayant Parekh \\ President, Indian Academy of Pediatrics 2020 \\ bakulparekh55@gmail.com
}

$\mathrm{D}$ ear IAPians, It gives me great pleasure to write to you about one of the most critical academic initiatives embarked upon by your Academy.

As the COVID-19 crisis has made us painfully aware, without connectivity and technology, it is impossible to function effectively in a locked-down world.

Even without this wake-up call, the whole world would agree that the Academy, just like all other organizations anywhere in the world, will transform into a Digital Academy. Organizations that do not have an underlying digital infrastructure with cutting edge capabilities will become increasingly ineffective and irrelevant, and fail to survive in the future.

IAPs own highly successful digital education efforts in the recent past, have made us aware of the immense possibilities and vastly enhanced capabilities that technology offers to an academic body like IAP.

No longer do we need to have any barriers of distance or cost to creating and disseminating education. We can also enhance the scope of our education to cover text material, lectures, panel discussions, workshops, case study discussions, and online clinics for doctors. We can conduct academic training from anywhere and access it from anywhere.

All our academic administration shall be made easy by our technology, whether it be registrations, payments, member services, local chapter websites, activities announcements, event calendars, and more.

Under the dIAP program, IAP has focused on building the end-to-end digital capabilities that a large scale teaching institute would require. We are now making the services available as a Digital Center of Excellence (DCOE), accessible on dIAP. The DCOE already includes online certificate courses with testing, an online interactive education platform, and an online reference library of text material and videos. DCOE is available to all IAP members and students of pediatrics.
You may access the education services on www.diapindia.org on your computer or using your mobile phone browser.

In this context, it gives me great pleasure to announce that IAP shall soon make the Indian College of Pediatrics (ICP) a reality. The Indian College of Pediatrics, an initiative by our Past President Dr CP Bansal in 2013, shall come alive next year and transform our academic activities. ICP will be a leading global university for pediatrics, spanning online, offline and hybrid education. I am confident that ICP will accelerate its launch and growth by leveraging the capabilities built by dIAP.

\section{MORE ABOUT DCOE}

The online certificate courses and testing services of the DCOE already have over 150 professionally recorded and edited lectures by IAP experts, and an additional 200 are under production. The lectures will cover all pediatrics areas and organized into over a hundred courses/ modules. The best part about these modules is that they can not only be used for online education, but also by all our local chapters as standardized education material for local IAP experts to conduct physical classroom sessions and hybrid sessions. The recording, professional editing, and publishing are done free of cost by dIAP for all subspecialty chapters.

The online interactive education platform of the DCOE has already conducted over 250 national events in the last three months. This capability is now being made available to all regional, state, and local chapters of IAP to hold online events for their members. For all education events, dIAP enables industry sponsorships. For those events where dIAP is unable to obtain grants or sponsors, dIAP is giving a full subsidy and conducting the events free of cost for the chapters.

The online reference library of DCOE has a searchable archive of over 400 educational videos. And many shall include expert advice forums for IAP members. 


\section{INDIAN COLLEGE OF PEDIATRICS}

The ICP is being revived, architected, and built as a significant initiative for launch in 2021. The ICP shall be an integral part of the Indian Academy of Pediatrics and serve as the highest academic wing of IAP.

DCOE capabilities shall accelerate the production and publishing of academic content for ICP. ICP will also acquire the administration and teaching capabilities of a full-fledged online university at no additional expense.

The DCOE shall itself be under the academic governance of the Indian College of Pediatrics. The Indian College of Pediatrics shall surely be the most comprehensive and large scale pediatrics university anywhere. Your Academy now has the capability to make this a reality, well before December, 2021.

Jai Hind! Jai IAP! 